\title{
NEURO-FUZZY APPROXIMATION OF MULTI-CRITERIA DECISION-MAKING QFD METHODOLOGY
}

\author{
Ajith Abraham ${ }^{1}$, Pandian Vasant ${ }^{2}$, and Arijit Bhattacharya ${ }^{3}$ \\ ${ }^{1}$ Center of Excellence for Quantifiable Quality of Service, Norwegian University of Science \\ and Technology, Trondheim, Norway ${ }^{2}$ EEE Program Research Lecturer Universiti \\ Teknologi Petronas, Perak DR, Malaysia ${ }^{3}$ Embark Initiative Post-Doctoral Research Fellow, \\ School of Mechanical \& Manufacturing Engineering, Dublin City University, Glasnevin, \\ Dublin 9, Ireland
}

\begin{abstract}
This chapter demonstrates how a neuro-fuzzy approach could produce outputs of a further-modified multi-criteria decision-making (MCDM) quality function deployment (QFD) model within the required error rate. The improved fuzzified MCDM model uses the modified S-curve membership function (MF) as stated in an earlier chapter. The smooth and flexible logistic membership function (MF) finds out fuzziness patterns in disparate level-of-satisfaction for the integrated analytic hierarchy process (AHP-QFD model. The key objective of this chapter is to guide decision makers in finding out the best candidate-alternative robot with a higher degree of satisfaction and with a lesser degree of fuzziness.
\end{abstract}

Key words: ANFIS, AHP, QFD, fuzziness patterns, decision-making, level-of-satisfaction

\section{INTRODUCTION}

Arriving at the decision to install a robot in a manufacturing firm can be a difficult and complicated process. Even after the initial decision to acquire a robot is made, the problem of which robot to select from the many that are available can confound managers who often lack the time and expertise to perform an extensive search and analysis. Furthermore, the current trend indicates that the number of robot manufacturers and suppliers are increasing as engineers continue to find more applications for robots. The 
problem of robot selection has become more difficult in recent years due to increasing complexity, available features, and facilities offered by different robotic products.

\subsection{Concepts on Neuro-Fuzzy Systems}

A fuzzy inference system (FIS) can use human expertise by storing its essential components in the rule base and the database and can perform fuzzy reasoning to infer the overall output value. The derivation of if-then rules and corresponding membership functions (MFs) depends heavily on the a priori knowledge about the system under consideration. However, there is no systematic way to transform experiences of knowledge of human experts into the knowledge base of an FIS. There is also a need for adaptability or some learning algorithms to produce outputs within the required error rate. On the other hand, ANN learning mechanism does not rely on human expertise. Due to the homogenous structure of ANN, it is hard to extract structured knowledge from either the weights or the configuration of the an artificial neural network (ANN). The weights of the ANN represent the coefficients of the hyperplane that partition the input space into two regions with different output values. If we can visualize this hyperplane structure from the training data, then the subsequent learning procedures in an ANN can be reduced. However, in reality, the a priori knowledge is usually obtained from human experts; it is most appropriate to express the knowledge as a set of fuzzy if-then rules, and it is not possible to encode into an ANN 0. Table 1 summarizes the comparison of FIS and ANN.

Table 1. Complementary Features of ANN and FIS

\begin{tabular}{ll}
\hline ANN & FIS \\
\hline Black box & Interpretable \\
Learning from scratch & Making use of linguistic knowledge \\
\hline
\end{tabular}

To a large extent, the drawbacks pertaining to these two approaches seem complementary. Therefore it is natural to consider building an integrated system combining the concepts of FIS and ANN modeling. A common way to apply a learning algorithm to a FIS is to represent it in a special ANN-like architecture 0. However, the conventional ANN learning algorithms (gradient descent) cannot be applied directly to such a system as the functions used in the inference process are usually nondifferentiable. This problem can be tackled by using differentiable 
functions in the inference system or by not using the standard neural learning algorithm. In our simulation, we used an adaptive network based fuzzy inference system (ANFIS) (Jang, 1991).

ANFIS implements a Takagi Sugeno Kang (TSK) fuzzy inference system (Jang, 1991) in which the conclusion of a fuzzy rule is constituted by a weighted linear combination of the crisp inputs rather than by a fuzzy set.

For a first-order TSK model, a common rule set with two fuzzy if-then rules is represented as follows:

Rule 1: If $x$ is $A_{1}$ and $y$ is $B_{1}$, then $f_{1}=p_{1} x+q_{1} y+r_{1}$

Rule 2: If $x$ is $A_{2}$ and $\mathrm{y}$ is $B_{2}$, then $f_{2}=p_{2} \mathrm{x}+q_{2} \mathrm{y}+r_{2}$ where $x$ and $y$ are linguistic variables and $A_{1}, A_{2}, B_{1}$, and $B_{2}$ are corresponding fuzzy sets and $p_{1}, q_{1}, r_{1}$ and $p_{2}, q_{2}, r_{2}$ are linear parameters.

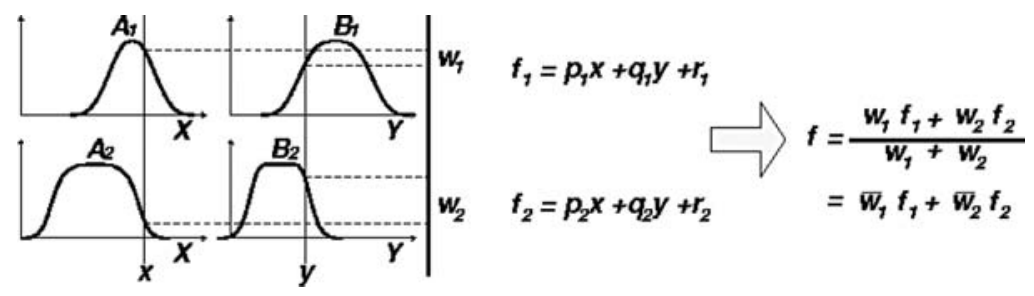

Figure 1. TSK-type fuzzy inference system

Figure 1 illustrates the TSK fuzzy inference system when two membership functions each are assigned to the two inputs ( $x$ and $y)$. The TSK fuzzy controller usually needs a smaller number of rules, because their output is already a linear function of the inputs rather than a constant fuzzy set.

Figure 2 depicts the five-layered architecture of ANFIS, and the functionality of each layer is as follows:

Layer-1. Every node in this layer has a node function

$$
\begin{aligned}
& O_{i}^{l}=\mu_{A i}(x), \text { for } \mathrm{i}=1, \text { or } 2 \\
& O_{i}^{1}=\mu_{B_{i-2}}(y), \text { for } \mathrm{i}=3,4, \ldots .
\end{aligned}
$$

$O_{i}^{1}$ is the membership grade of a fuzzy set $A$ ( $=A_{1}, A_{2}, B_{1}$ or $\left.B_{2}\right)$, and it specifies the degree to which the given input $x$ (or $y$ ) satisfies the quantifier $A$. Usually the node function can be any parameterized function. 
A Gaussian membership function is specified by two parameters $c$ (membership function center) and $\sigma$ (membership function width).

\section{ADAPTIVE NETWORK-BASED FUZZY INFERENCE SYSTEM (ANFIS)}

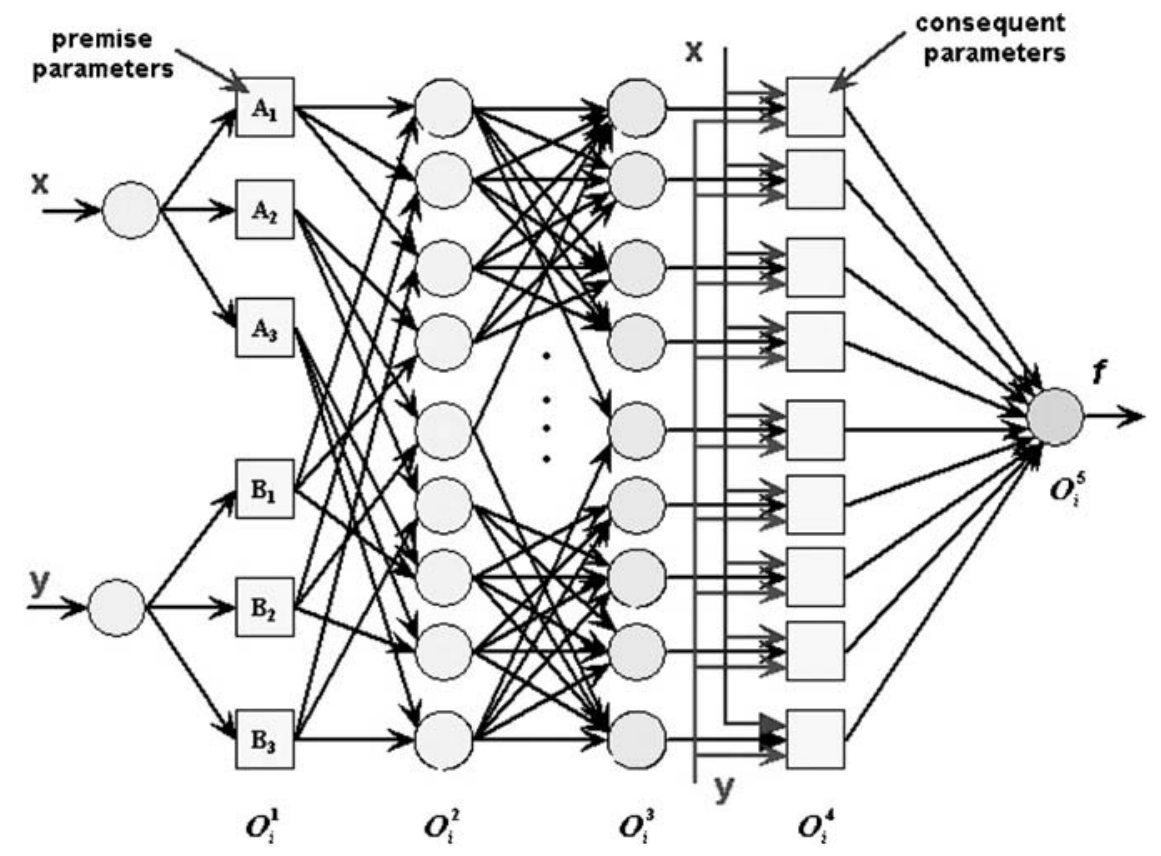

Figure 2. Architecture of the ANFIS

Guassian $(x, c, \sigma)=e^{-\frac{1}{2}\left(\frac{x-c}{\sigma}\right)^{2}}$.

Parameters in this layer are referred to as premise parameters.

Layer-2. Every node in this layer multiplies the incoming signals and sends the product out. Each node output represents the firing strength of a rule.

$$
O_{i}^{2}=w_{i}=\mu_{A i}(x) \times \mu_{B i}(y), i=1,2 .
$$

In general any T-norm operators perform fuzzy AND can be used as the node function in this layer. 
Layer-3. Every $i$ th node in this layer calculates the ratio of the $i$ th rule's firing strength to the sum of all rule's firing strength.

$$
O_{i}^{3}=\overline{w_{i}}=\frac{w_{i}}{w_{1}+w_{2}}, i=1,2
$$

Layer-4. Every node $i$ in this layer is with a node function

$$
O_{1}^{4}=\overline{w_{i}} f_{i}=\overline{w_{i}}\left(p_{i} x+q_{i} y+r_{i}\right)
$$

where $\overline{w_{i}}$ is the output of layer-3, and $\left\{p_{i}, q_{i}, r_{i}\right\}$ is the parameter set. Parameters in this layer will be referred to as consequent parameters.

Layer-5. The single node in this layer computes the overall output as the summation of all incoming signals:

$$
O_{1}^{5}=\text { Overall output }=\sum_{i} \bar{w}_{i} f_{i}=\frac{\sum_{i} w_{i} f_{i}}{\sum_{i} w_{i}}
$$

ANFIS makes use of a mixture of backpropagation to learn the premise parameters and least mean square estimation to determine the consequent parameters. A step in the learning procedure has two parts: In the first part, the input patterns are propagated, and the optimal conclusion parameters are estimated by an iterative least mean square procedure, whereas the antecedent parameters (membership functions) are assumed to be fixed for the current cycle through the training set. In the second part, the patterns are propagated again, and in this epoch, backpropagation is used to modify the antecedent parameters, whereas the conclusion parameters remain fixed. This procedure is then iterated (Jang, 1991).

\section{QFD PROCESS}

QFD is a method for structured product planning and development. It enables a development team to specify clearly the customer's requirement. It also evaluates each proposed product systematically in terms of its impact on meeting those requirements (Hauser and Clausing, 1988; Wasserman, 1993). It is also an important tool for concurrent engineering. In the era of globalization, the customer's order decoupling point (CODP) 
is at make-to-order (MTO) stage (Bhattacharya et al., 2005). From Figure 1 it is understood where to apply the QFD process. QFD is used at a CODP to ensure that the voice of the customer is heard throughout the product planning and design stage (Franceschini and Rosetto, 1995). QFD, in fact, is a method of continuous product improvement, emphasizing the impact of organizational learning on innovation (Govers, 2001).

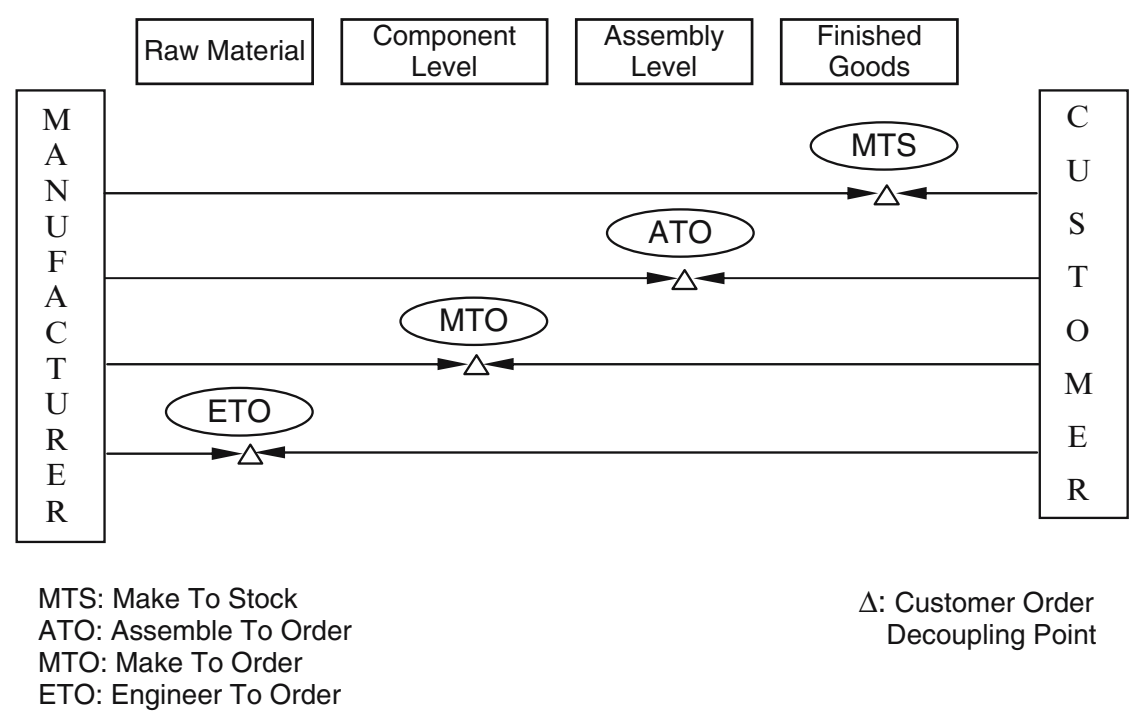

Figure 3. Relationship between CODP and MCDM-QFD process

(Bhattacharya et al., 2005)

In QFD process, a matrix called the house-of-quality (HOQ) (Hauser and Clausing, 1988) is used to display the relationship between the voice of customers (WHATs) and the quality characteristics (HOWs) (Chuang, 2001). WHATs and HOWs are nothing but the customer and technical requirements, respectively. The HOQ is developed during the QFD transformation. Basically the HOQ demonstrates how the technical requirements satisfy the customer requirements. The matrix highlights the important issues in the planning of a new product or improving an existing product. QFD, when combining WHATs and HOWs with competitive analysis (WHYs), represents a customer-driven and market-oriented process for decision making (Cohen, 1995).

A traditional QFD model uses absolute importance to identify the degree of importance for each customer requirement. The psychology of customers, in general, is to rate almost everything as equally important, 
although it is not. As the absolute weighing data tend to be bunched near the highest possible scores, the differentiation of customer requirements is thus strongly recommended. These data, as they are, do not contribute much to helping QFD developers in prioritizing technical responses. At this juncture, the AHP (Saaty, 1988; 1990; 1994) prioritizes the customer's requirements by putting the relative degree of importance to each customer-requirement.

The task of the QFD team is to list the technical requirements (TRs). These requirements are most likely to affect the CRs. TR evaluators, in the QFD team, evaluate how the competitors' products compare with that of company's product. This evaluation leads to fixing of technical targets. From the QFD matrix, the discrepancies, if any, between the customers' perception and the QFD team's correlation of CR and TR can be easily understood. The vertical part of the QFD matrix shows how the company may respond to customer requirements.

\section{DEVELOPMENT OF THE COMBINED AHP-QFD METHODOLOGY}

The methodology integrating the MCDM methodology (AHP) and QFD for a selection problem comprises the following steps and is shown in Figure 4:

Step 1. Identification of customer requirements.

Step 2. Identification of technical requirements.

Step 3. Construction of central relationship matrix using expert knowledge of QFD team.

Step 4. Computation of degree of importance for customer requirements by using AHP.

Step 5. Computation of the degree of importance of technical requirements by Eq. (1).

$$
w_{j}=\sum_{i=1}^{m} R_{i j} c_{i}
$$

where

$w_{j}=$ importance degree of the $j$ th technical requirement $(\forall j=1,2, \ldots, \mathrm{n})$,

$R_{i j}=$ quantified relationship between the $i$ th customer requirement and the $j$ th technical criteria in the central relationship matrix, and $c_{i}=$ importance weighing of the $i$ th customer requirement. 


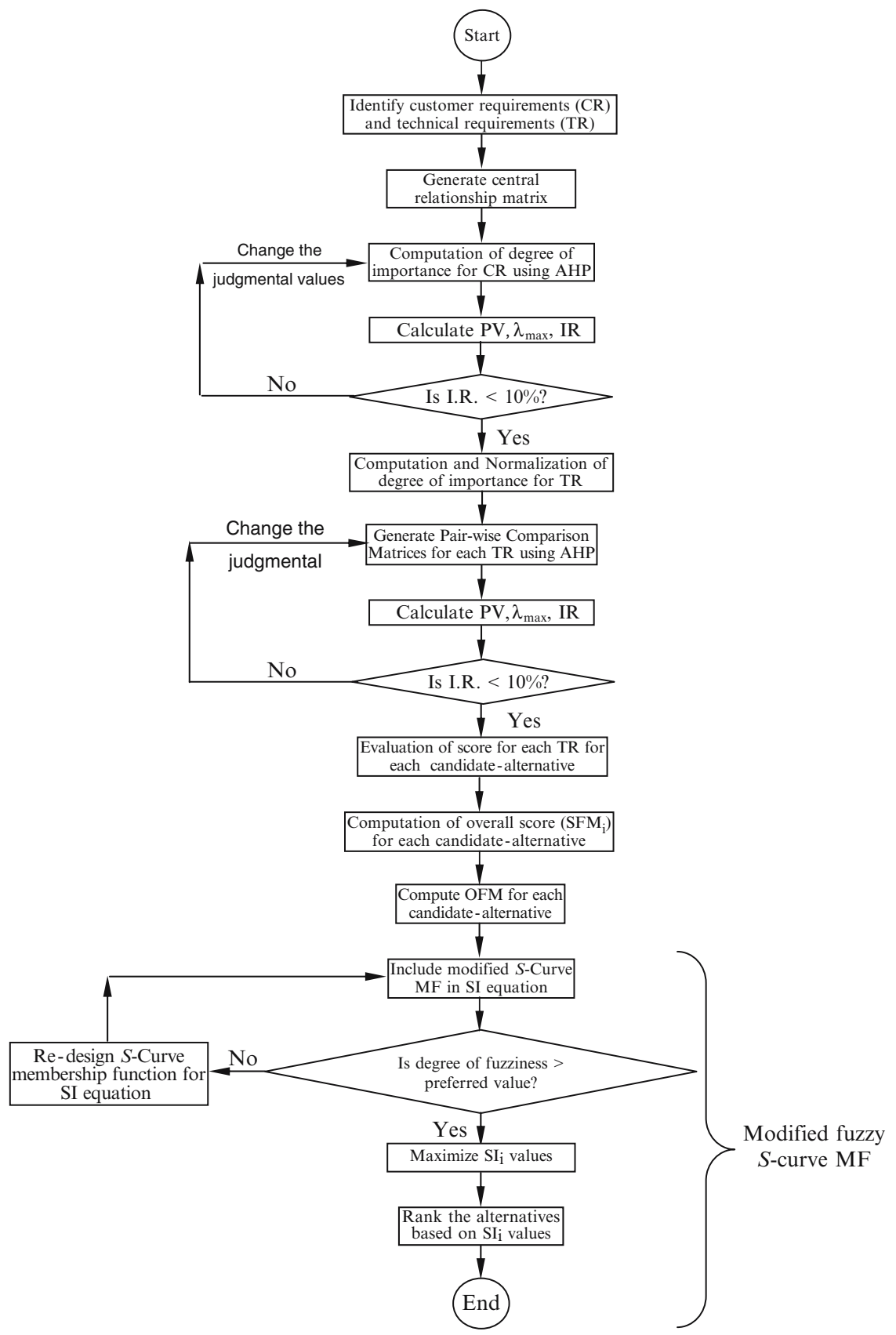

Figure 4. Flowchart of the proposed methodology 
Step 6. Normalization of the degree of importance of technical criteria by Eq. (2).

$$
\bar{w}_{j}=\frac{w_{j}}{\sum_{j=1}^{n} w_{j}} \times 100
$$

Step 7. Construction of pair-wise comparison matrices for each technical requirement using Saaty's $(1988 ; 1990)$ nine-point scale.

Step 8. Evaluation of score, $w_{i j}$, for each technical requirement for each candidate-alternative.

Step 9. Computation of overall score (Chuang, 2001) by using Eq. (3).

$$
S_{j}=\sum_{j=1}^{n} \bar{w}_{j} e_{i j}
$$

where,

$S_{j}=$ overall score for the $j$ th candidate-alternative $(\forall j=1,2, \ldots, \mathrm{n})$,

$\bar{w}_{j}=$ normalized importance degree of the $j$ th technical criteria $(j=1,2, \ldots, \mathrm{n})$, and

$e_{i j}=\mathrm{PV}$ value of the $j$ th alternative on the $i$ th technical criteria Eq. 4.

Step 10. Computation of OFM values for each candidate robot by using

OFM $=$ Objective Factor Measure,

OFC $=$ Objective Factor Cost,

SFM $=$ Subjective Factor Measure,

SI = Selection Index,

$\alpha=$ Objective factor decision weight, and

$n=$ number of candidate-alternatives $(n=4$ in for the robot selection problem).

$$
\mathrm{OFM}_{i}=\left[\mathrm{OFC}_{i} \times \Sigma\left(\mathrm{OFC}_{i}^{-1}\right)\right]^{-1}
$$

Step 11. Identification of fuzziness patterns and measurement of levelof- satisfaction of the decision maker using modified $S$-curve MF.

Step 12. Re designing the MF if the degree of fuzziness is greater than a preferred value.

Step 13. Maximization of the SI (selection index) value using Eq. 5.

$$
\mathrm{SI}_{i}=\left[\left(\alpha \times \mathrm{SFM}_{i}\right)+(1-\alpha) \times \mathrm{OFM}_{i}\right]
$$


Step 14. Ranking of all the candidate-alternatives

Step 15. Selection of the best candidate-alternative using the analogy the higher the score, the better the selection.

\section{ROBOT SELECTION PROBLEM}

An illustrative example of a process industry dealing with an enormous volume of manufactured product was illustrated by Bhattacharya et al. (2005). Out of four robots, the best-suited robot was purchased for the desired job for a very specific manufacturing process using the methodology of combined AHP-QFD as depicted by Bhattacharya et al. (2005). But what is lacking in the said proposed model of Bhattacharya et al. (2005) is the evaluation of the fuzzy parameters in their multi-criteria selection model. When fuzzy parameters like human expertise and linguistic knowledge get involved with the model, there is always a need for the model to approximate the outputs within the required error rate. Thus, the ANFIS (Jang, 1991) is found suitable in dealing with this complex problem of multi-criteria decision making. Considering the robot selection data of Bhattacharya et al. (2005) we begin with fitting the modified S-curve MF (Eq. 6) in their methodology. Step 11 onward of the methodology have been proposed herein with the fuzzy S-curve MF.

$$
\mu(x)= \begin{cases}1 & x<x^{a} \\ 0.99 & x=x^{a} \\ \frac{B}{1+C e^{y x}} & x^{a}<x<x^{b} \\ 0.001 & x=x^{b} \\ 0 & x>x^{b}\end{cases}
$$

We use the previously identified customer requirements (CRs) viz., payload, accuracy, life-expectancy, velocity, programming flexibility and total cost of robot, and seven TRs, viz., drive system, geometrical dexterity, path measuring system, size, material, weight and initial operating cost of robot. As in the case of Bhattacharya et al. (2005) the job is to select the best one of the four robots. The additional purposes of the current model are to view the fuzziness patterns as well as the level-of- 
satisfaction of the decision maker, and to approximate the model with a predetermined allowable error rate.

For measuring the relative degree of importance for each customer requirement, based on the proposed methodology, a $(6 \times 6)$ decision matrix is constructed and shown in Figure 5.

$$
\mathbf{D}=\left[\begin{array}{llllll}
1 & 7 & 3 & 4 & 5 & 9 \\
1 / 7 & 1 & 1 / 3 & 1 / 2 & 2 & 3 \\
1 / 3 & 3 & 1 & 3 & 6 & 2 \\
1 / 4 & 2 & 1 / 3 & 1 & 3 & 4 \\
1 / 5 & 1 / 2 & 1 / 6 & 1 / 3 & 1 & 1 / 7 \\
1 / 9 & 1 / 3 & 1 / 2 & 1 / 4 & 7 & 1
\end{array}\right]=\left[\begin{array}{llllll}
1 & 7 & 3 & 4 & 5 & 9 \\
0.143 & 1 & 0.333 & 0.500 & 2 & 3 \\
0.333 & 3 & 1 & 3 & 6 & 2 \\
0.250 & 2 & 0.333 & 1 & 3 & 4 \\
0.200 & 0.500 & 0.167 & 0.333 & 1 & 0.143 \\
0.111 & 0.333 & 0.500 & 0.250 & 7 & 1
\end{array}\right]
$$

Figure 5. Decision matrix

The PV values of this decision matrix are found and $\lambda_{\max }$, I.I., R.I., and I.R. are calculated. If the level of inconsistency present in the information stored in the " $\mathrm{D}$ " matrix is satisfactory, the QFD team, then, puts the PV values in the transformation matrix. The next job of the QFD team is to find out the ranking of the given four robots based on the seven conflicting TRs. Seven pair-wise comparison matrices were built up based on the information on each TR.

Table 2. Overall Scores of the Four Robots

\begin{tabular}{|c|c|c|c|c|c|c|c|c|}
\hline \multirow{2}{*}{$\begin{array}{l}\text { Technical } \\
\text { Requirements }\end{array}$} & \multirow[t]{2}{*}{ Weight } & \multicolumn{4}{|c|}{ Importance weight for robots } & \multirow[t]{2}{*}{ I.I. } & \multirow[t]{2}{*}{ I.R. } & \multirow{2}{*}{$\begin{array}{l}\text { Inconsistency } \\
(\%)\end{array}$} \\
\hline & & $\mathrm{R}_{1}$ & $\mathrm{R}_{2}$ & $\mathrm{R}_{3}$ & $\mathrm{R}_{4}$ & & & \\
\hline $\begin{array}{l}\text { 1. Drive } \\
\text { system }\end{array}$ & 31.54 & 0.529 & 0.094 & 0.314 & 0.063 & 0.0249 & 0.0252 & 2.52 \\
\hline $\begin{array}{l}\text { 2.Geometrical } \\
\text { dexterity }\end{array}$ & 8.64 & 0.147 & 0.281 & 0.514 & 0.059 & 0.0116 & 0.0117 & 1.17 \\
\hline $\begin{array}{l}\text { 3. Path } \\
\text { measuring } \\
\text { system }\end{array}$ & 9.47 & 0.074 & 0.520 & 0.105 & 0.300 & 0.0842 & 0.0851 & 8.51 \\
\hline 4. Robot size & 9.36 & 0.267 & 0.550 & 0.054 & 0.128 & 0.0644 & 0.0651 & 6.51 \\
\hline $\begin{array}{l}\text { 5. Material of } \\
\text { robot }\end{array}$ & 9.05 & 0.319 & 0.532 & 0.092 & 0.057 & 0.0866 & 0.0875 & 8.75 \\
\hline $\begin{array}{l}\text { 6. Weight of } \\
\text { robot }\end{array}$ & 26.46 & 0.523 & 0.089 & 0.326 & 0.062 & 0.0369 & 0.0373 & 3.73 \\
\hline $\begin{array}{l}\text { 7. Initial } \\
\text { operating } \\
\text { cost }\end{array}$ & 5.48 & 0.483 & 0.086 & 0.355 & 0.077 & 0.0748 & 0.0756 & 7.56 \\
\hline Overall score & & 40.53 & 23.11 & 27.25 & 9.11 & & & \\
\hline
\end{tabular}


Table 2 suggests $\mathrm{R}_{1}$ » $\mathrm{R}_{3}$ » $\mathrm{R}_{2}$ » $\mathrm{R}_{4}$; i.e., $\mathrm{R}_{1}$ gets precedence over $\mathrm{R}_{3}$, which gets more importance over $R_{2}$ and $R_{4}$. Thus, the robot $R_{1}$ is selected as it has the highest overall score compared with others.

The total cost of the robotic system described in Bhattacharya et al. (2005) were broken down (refer to Table 3).

Table 3. Cost Factor Components and Their Units

\begin{tabular}{ll}
\hline Cost factor components & Range of attribute values \\
\hline 1. Acquisition cost of robot & US $\$ 4500-7000 /$ unit \\
2. Cost of robot gripper mechanisms & US $\$ 2500-3000$ \\
3. Cost of sensors & US $\$ 900-1200$ \\
$\begin{array}{l}\text { 4. Total cost of layout necessary for } \\
\text { installation of robot }\end{array}$ & US $\$ 3500-4000$ \\
5. Cost of feeders & US $\$ 400-900 /$ unit \\
6. Maintenance cost & US $\$ 500-650 /$ week \\
7. Cost of energy & US $\$ 6-10 /$ Unit of electrical energy \\
\hline
\end{tabular}

The cost factors in Table 3 involve two types of costs, both a fixed and a recurring type. For four different robots, of which each can perform the very specified job, the attributes of the cost components are tabulated in Table 4.

Table 4. Attributes of Cost Factor Component

\begin{tabular}{lllll}
\hline Robots & $\mathrm{R}_{1}$ & $\mathrm{R}_{2}$ & $\mathrm{R}_{3}$ & $\mathrm{R}_{4}$ \\
\cline { 1 - 4 } Cost components & & & & \\
\hline 1. Acquisition cost of robot & 6500 & 5000 & 7000 & 4500 \\
2. Cost of robot gripper mechanisms & 2750 & 2500 & 3000 & 2900 \\
3. Cost of sensors & 1200 & 950 & 1100 & 1000 \\
4. Total cost of layout & 3650 & 4000 & 3875 & 3500 \\
5. Cost of feeders & 900 & 765 & 400 & 860 \\
6. Maintenance cost & 480 & 900 & 730 & 400 \\
7. Cost of energy & 7 & 8 & 10 & 6 \\
Total (OFC) (US\$) & 15487 & 14123 & 16115 & 13166 \\
\hline
\end{tabular}

A mathematical model was proposed by Bhattacharya et al. (2005) to combine cost factor components with the importance weightings found from AHP. The governing equation of the said model is

$$
\mathrm{SI}_{i}=\left[\left(\alpha \times \mathrm{SFM}_{i}\right)+(1-\alpha) \times \mathrm{OFM}_{i}\right]
$$

where, 


$$
\mathrm{OFM}_{i}=\frac{1}{\left[\mathrm{OFC}_{i} \times \sum_{i=1}^{n} \mathrm{OFC}^{-1}\right]}
$$

In the following chapters, we have discussed the implications of Eq. (8) as well as the modified S-curve MF with reference to the targeted MCDM modeling. Therefore, we refrain to discuss on these basic equations.

\subsection{Computation of Level-of-Satisfaction, Degree of Fuzziness}

We confine our efforts assuming that differences in judgmental values are only $5 \%$. Therefore, the upper bound and lower bound of $\mathrm{SFM}_{\mathrm{i}}$ as well as $\mathrm{SI}_{\mathrm{i}}$ indices are to be computed within a range of $5 \%$ of the original value reported by Bhattacharya et al. (2005). In order to avoid complexity in delineating the technique proposed herein, we have considered, 5\% measurement. One can fuzzify the $\mathrm{SFM}_{\mathrm{i}}$ values from the very beginning of the AHP-QFD model by introducing a modified $S$-curve MF in AHP, and the corresponding fuzzification of $\mathrm{SI}_{\mathrm{i}}$ indices can also be carried out using their holistic approach.

By using the equations above for a modified $S$-curve MF a relationship among the level-of-satisfaction of the decision maker, the degree of vaguenes and the SI indices is found. The results are plotted accordingly.

Figures $5 \mathrm{a}, \mathrm{b}$ and $\mathrm{c}$ show three different plots depicting a relation among the level-of-satisfaction and SI indices for three different vagueness values. It should always be noted that higher the fuzziness, $\gamma$, values, the lesser will be the degree of vagueness inherent in the decision. Therefore, it is understood that the higher level of outcome of the decision variable, SI, for a particular level-of-satisfaction point, results in a lesser degree of fuzziness inherent in the said decision variable.

A relationship between the degree of fuzziness, $\gamma$, and the level-ofsatisfaction $\alpha$ has been depicted by Figure 6 . This is a clear indication that the decision variables, as defined in Eqs. (6) and (7), allows the MCDM model to achieve a higher level-of-satisfaction with a lesser degree of fuzziness.

Figures 7 and 8 delineate SI indices versus level-of-satisfaction $\alpha$ and SI indices versus degree of fuzziness $\gamma$, respectively. Now, let us examine the fuzziness inherent in each candidate-alternative.

There is a need to calculate both the upper bound and the lower bound solution of SI indices having a different level-of-satisfaction $(\alpha)$. The 
following figures have been found using MATLAB ${ }^{\circledR}$ version 7.0. The results have been encouraging, and the corresponding results have been indicated in Figures 9 to 14.

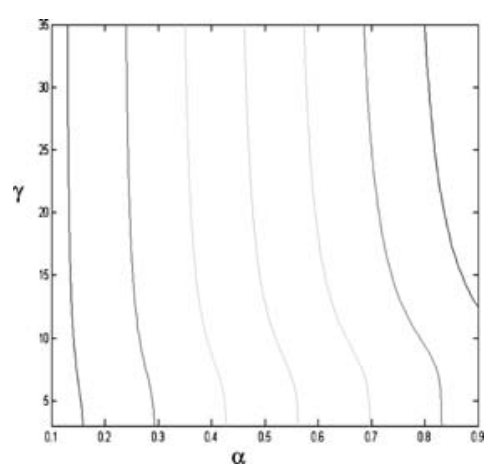

Figure 6. Fuzziness vs. $\alpha$ for Robot 1

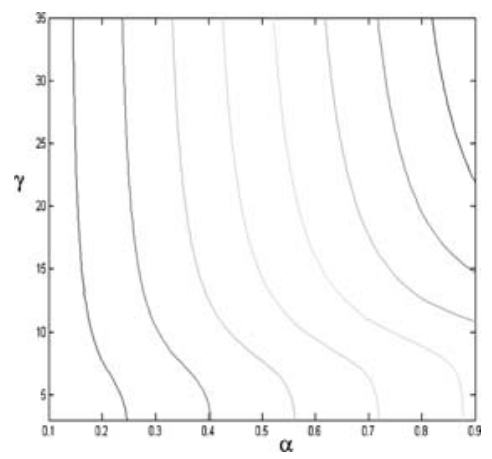

Figure 8. Fuzziness vs. $\alpha$ for Robot 3

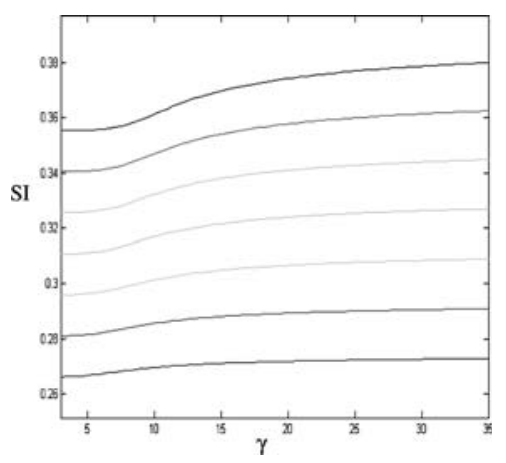

Figure 10. SI vs. $\gamma$ for Robot 1

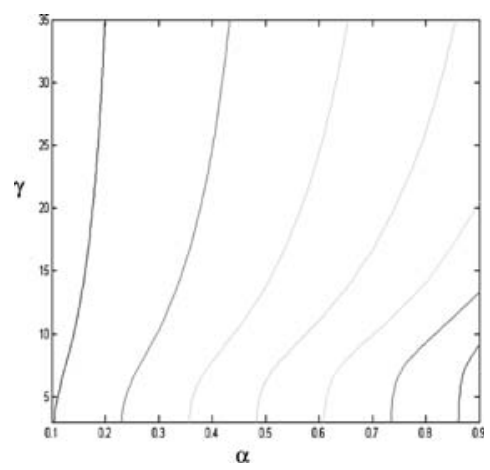

Figure 7. Fuzziness vs. $\alpha$ for Robot 2

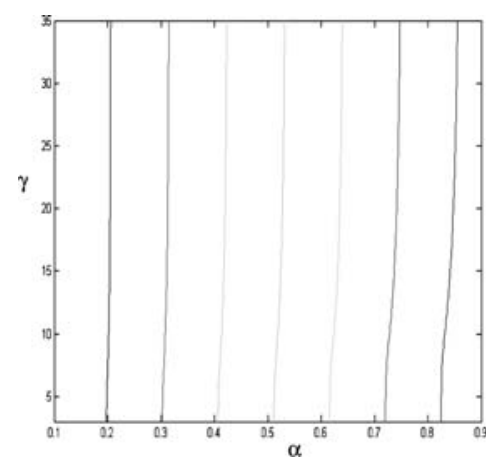

Figure 9. Fuzziness vs. $\alpha$ for Robot 4

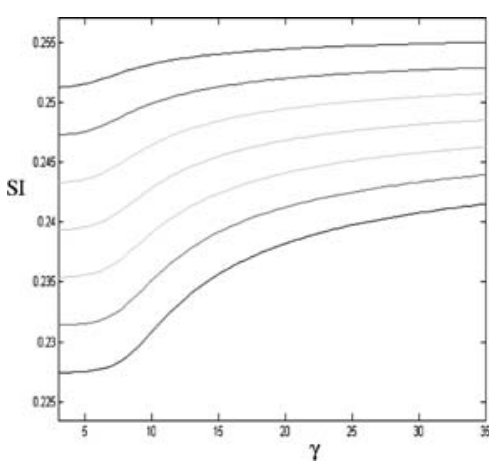

Figure 11. SI vs. $\gamma$ for Robot 2 


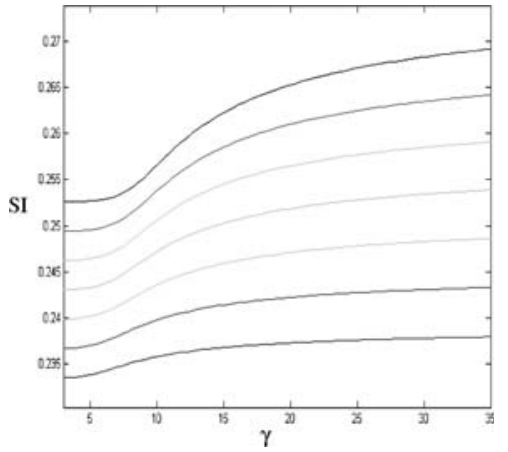

Figure 12. SI vs. $\gamma$ for Robot 3

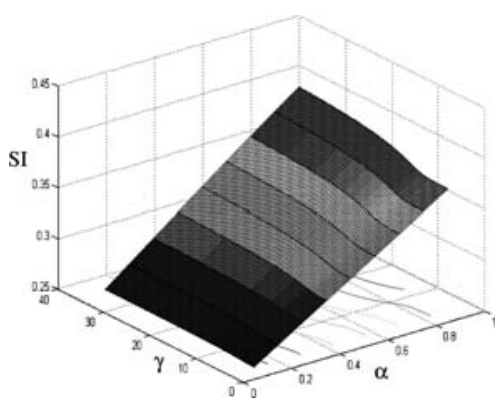

Figure 14. SI, $\gamma$, and $\alpha$ for Robot 1

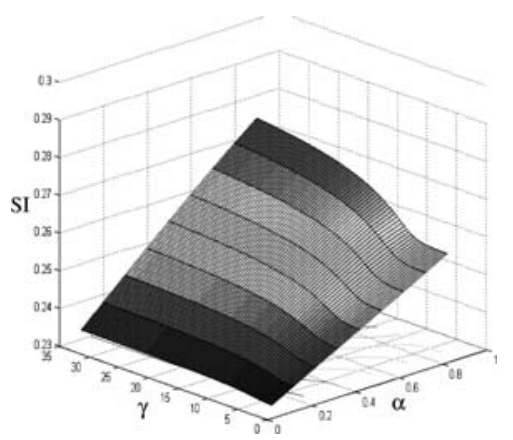

Figure 16. SI, $\gamma$, and $\alpha$ for Robot 3

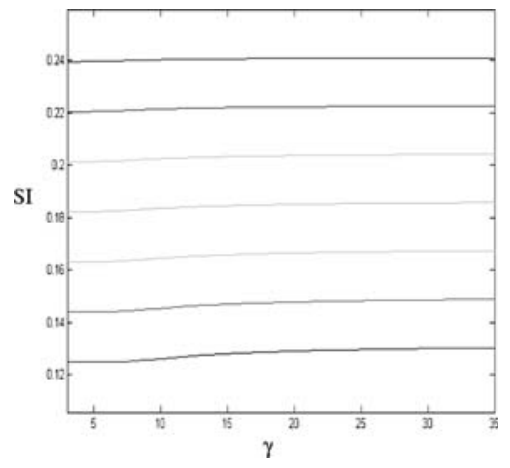

Figure 13. SI vs. $\gamma$ for Robot 4

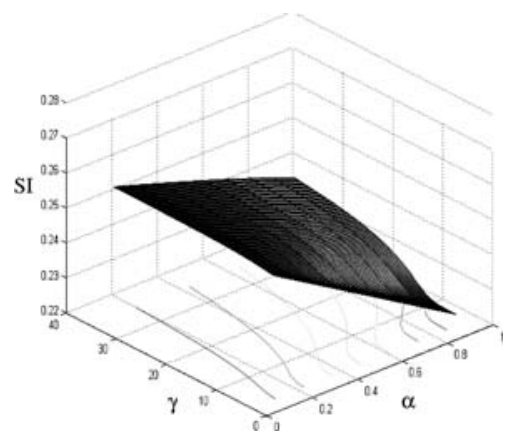

Figure 15. SI, $\gamma$, and $\alpha$ for Robot 2

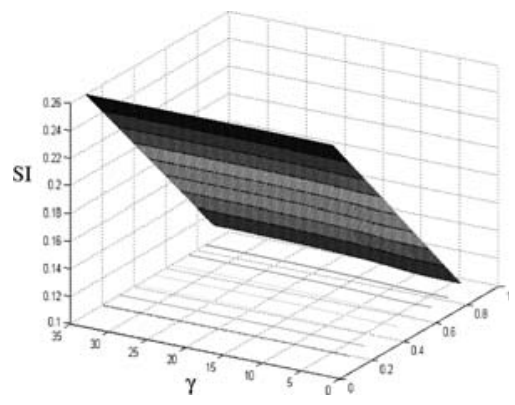

Figure 17. SI, $\gamma$, and $\alpha$ for Robot 4 
Thus, the decision for selecting a candidate-alternative as seen from Figures 9 to 13 is tabulated in Table 5. It is noticed from the current investigation that this model eliciting the degree of fuzziness corroborates the MCDM model without fuzzification presented in Bhattacharya et al. (2005).

\subsection{Experiment Results using the ANFIS Model}

The experimental system consists of two stages: network training and performance evaluation. The task is to approximate the values of SI for different values of $\alpha$ and $\gamma$. In this chapter, we developed fuzzy inference systems for varying values of gamma keeping $\alpha=0.001,0.2,0.4,0.6,0.8$, and 1.0. Takagi Sugeno fuzzy inference was used with linear consequent parameters. We used four Gaussian MFs for the two variables $\alpha$ and $\gamma$. Sixteen fuzzy if-then rules were created during the neural learning process as depicted in Figures 18, 20, 22, 24, 26 and 28. The learned surfaces showing the input/output are illustrated in Figures 19, 21, 23, 25, 27 and 29. Empirical results are depicted in Table 5.

Table 5. Performance of the Fuzzy Inference Systems

\begin{tabular}{ll}
\hline$\alpha$ value & Root Mean Squared Error \\
\hline 0.001 & 0.0004 \\
0.2 & 0.0009 \\
0.4 & 0.0004 \\
0.6 & 0.002 \\
0.8 & 0.002 \\
1.0 & 0.004 \\
\hline
\end{tabular}
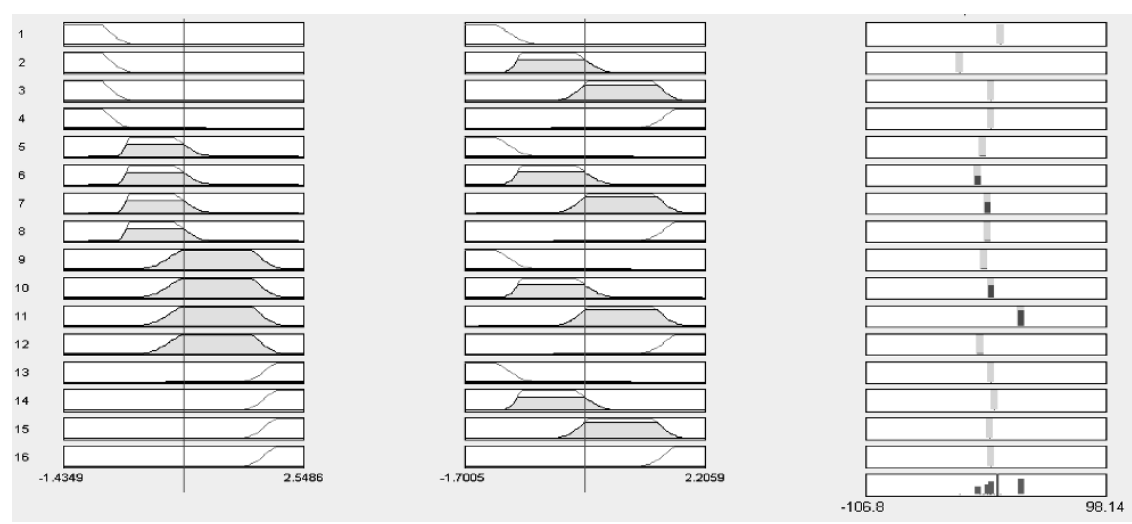

Figure 18. Developed Takagi Sugeno FIS $(\alpha=0.001)$ 


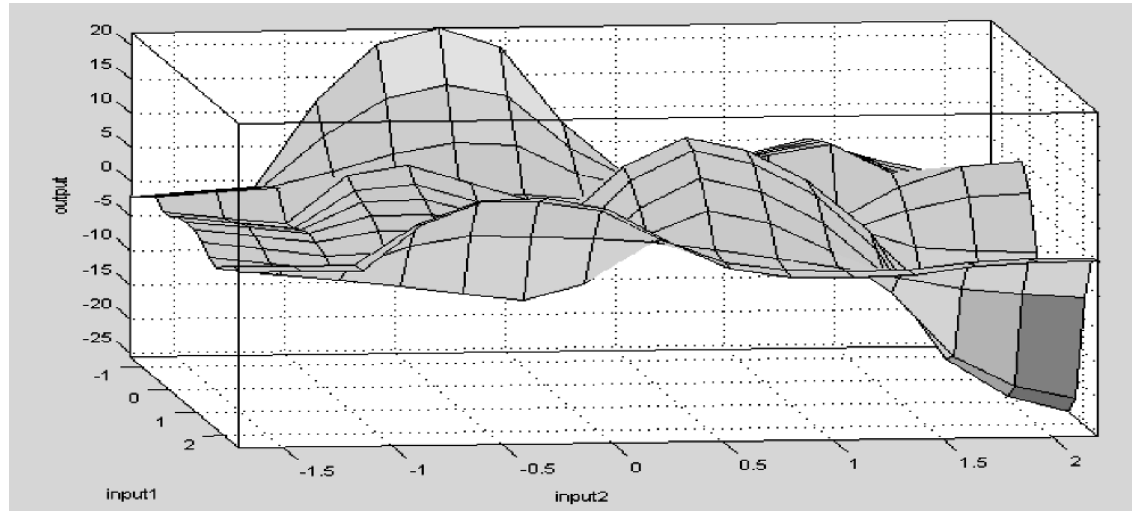

Figure 19. Input/Output surface mapping $(\alpha=0.001)$
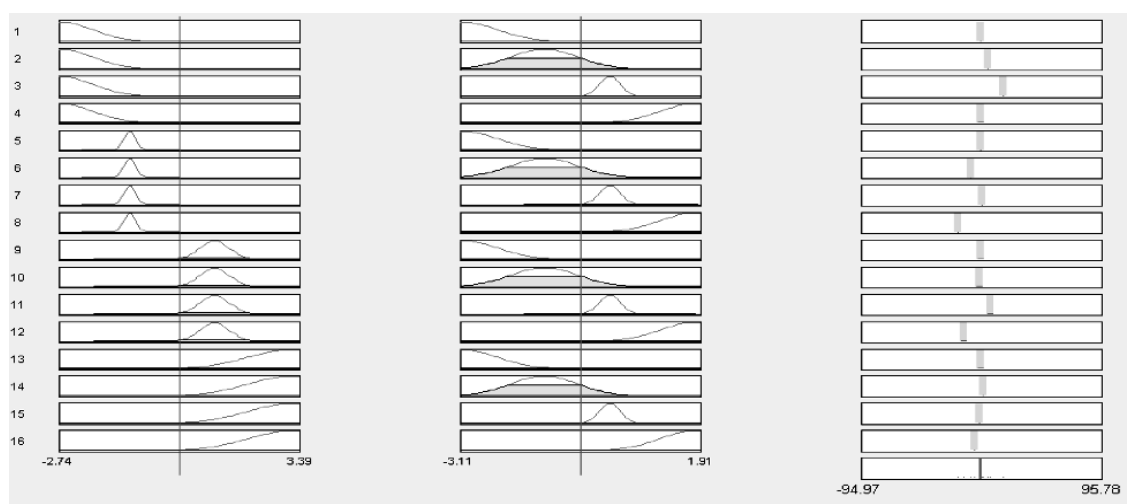

Figure 20. Developed Takagi Sugeno fuzzy inference system $(\alpha=0.2)$

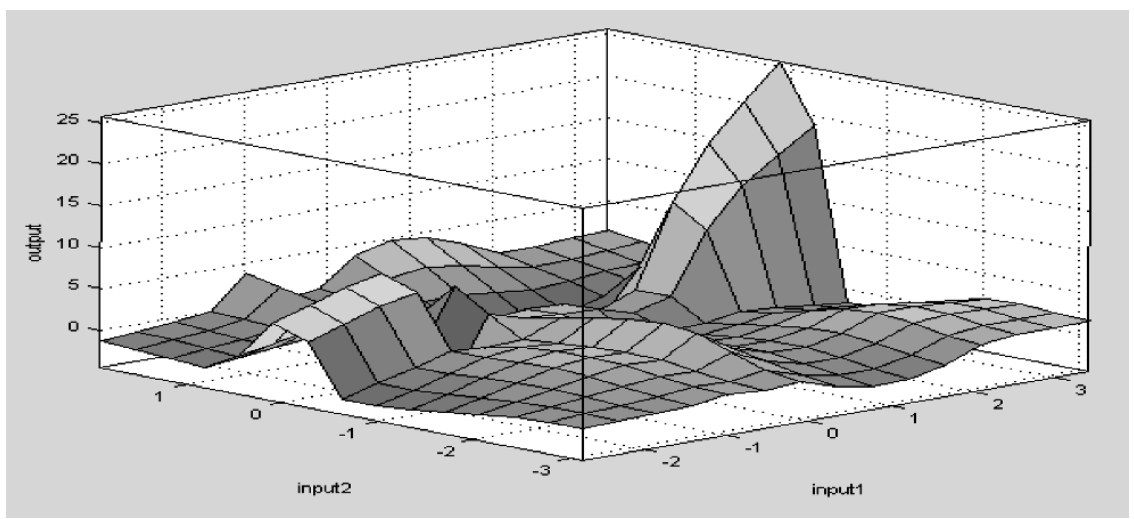

Figure 21. Input/Output surface mapping $(\alpha=0.2)$ 

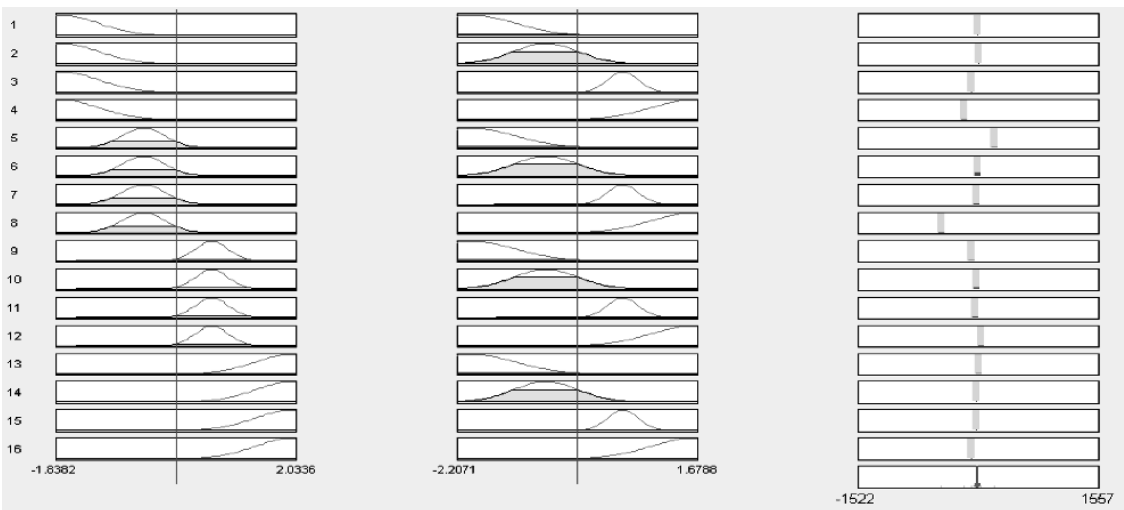

Figure 22. Developed Takagi Sugeno fuzzy inference system $(\alpha=0.4)$

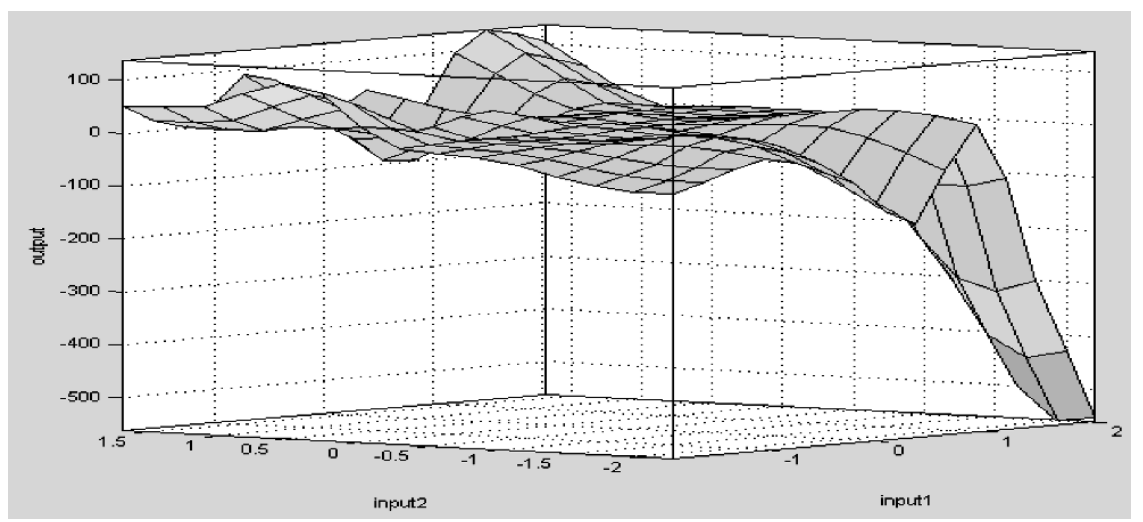

Figure 23. Input/Output surface mapping $(\alpha=0.4)$
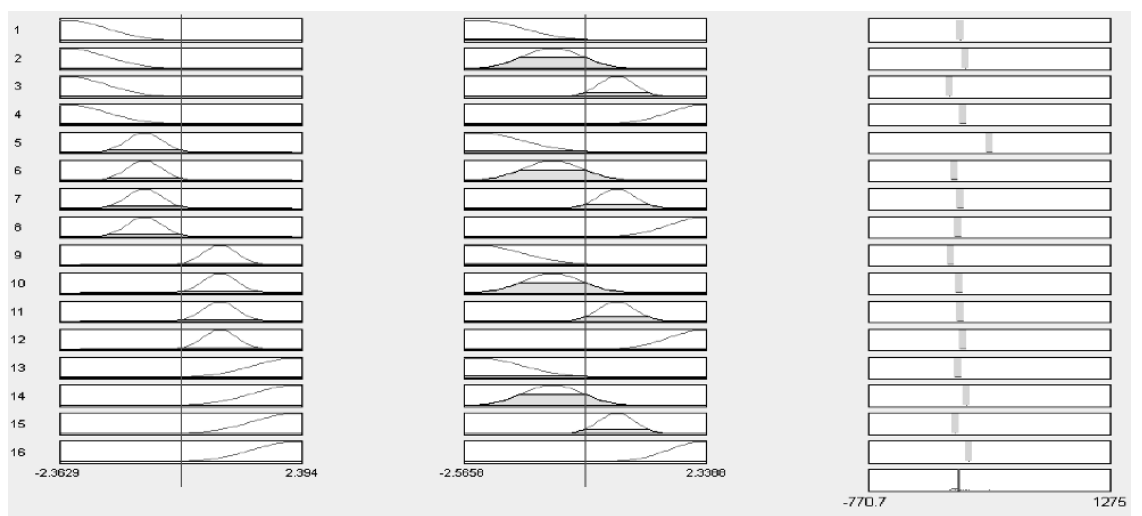

Figure 24. Developed Takagi Sugeno fuzzy inference system $(\alpha=0.6)$ 


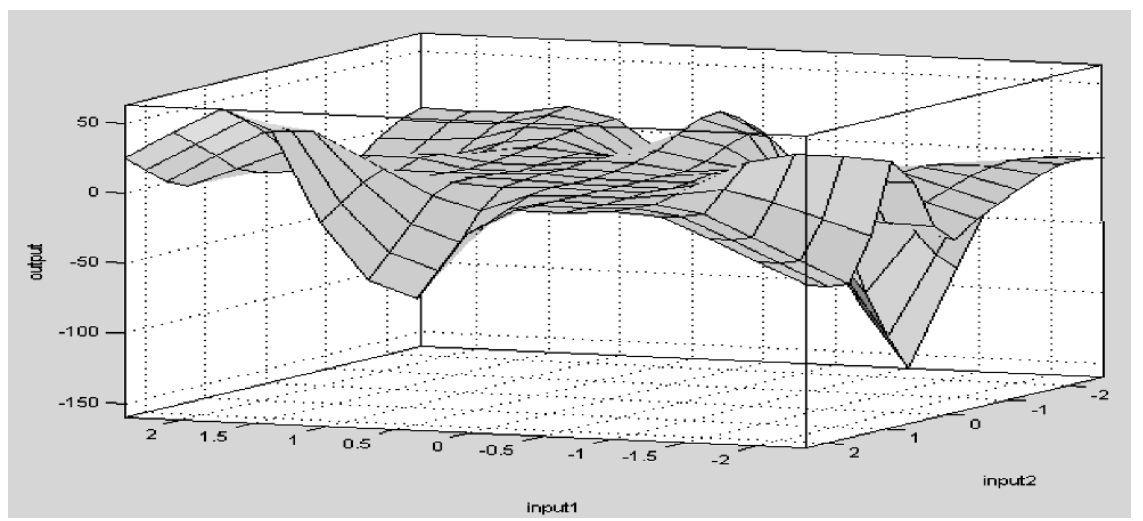

Figure 25. Input/Output surface mapping $(\alpha=0.6)$
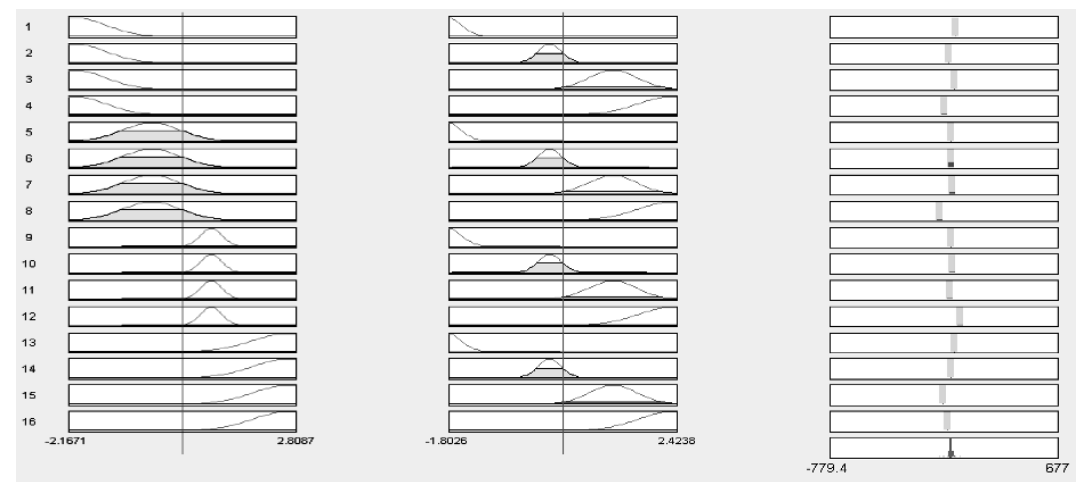

Figure 26. Developed Takagi Sugeno fuzzy inference system $(\alpha=0.8)$

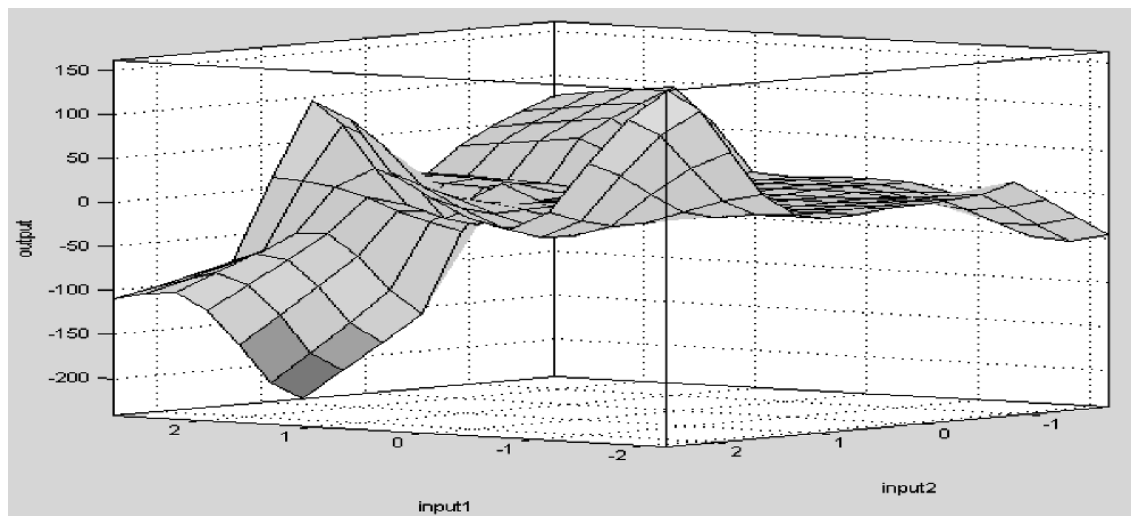

Figure 27. Input/Output surface mapping $(\alpha=0.8)$ 

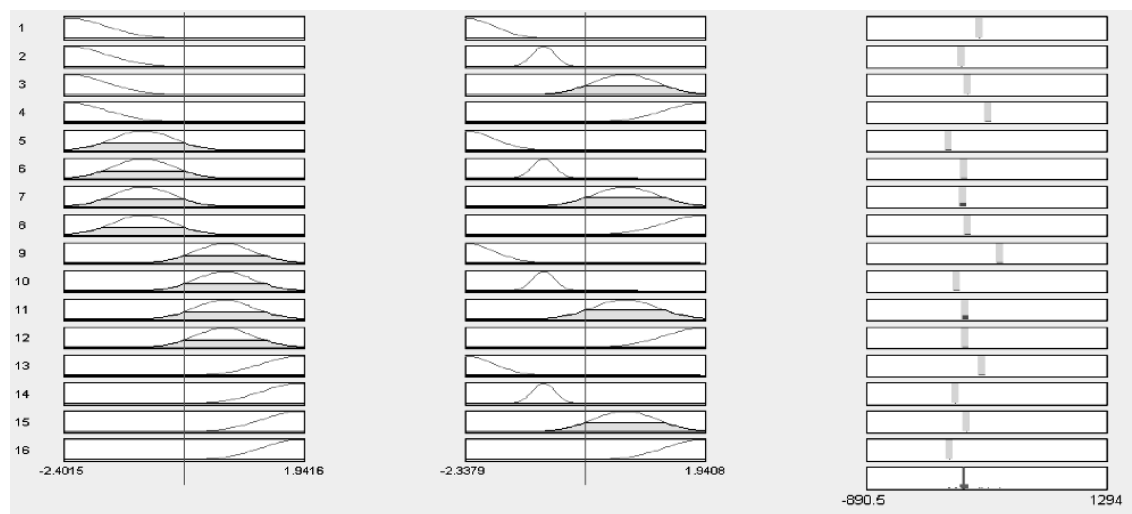

Figure 28. Developed Takagi Sugeno fuzzy inference system $(\alpha=1.0)$

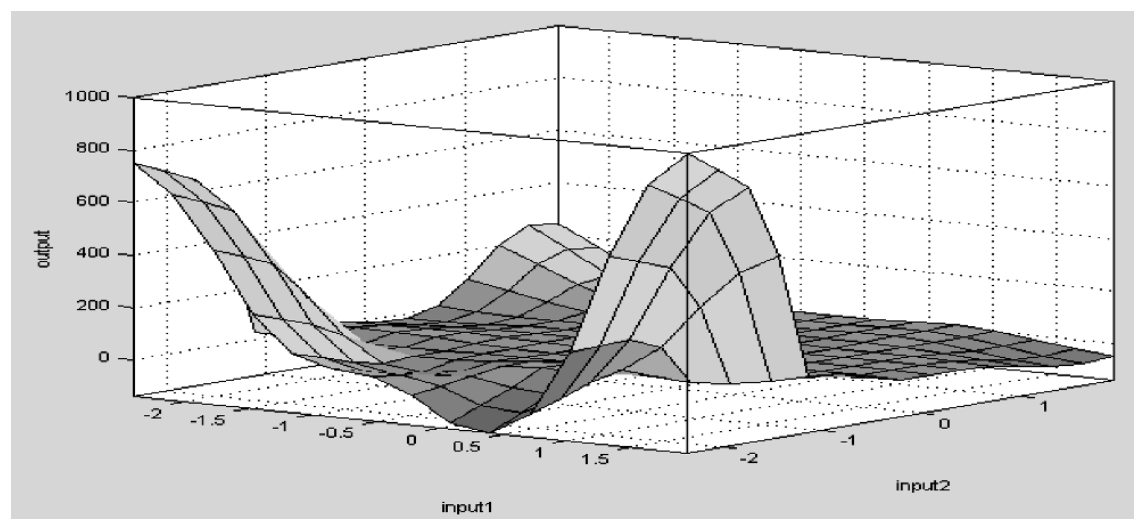

Figure 29. Input/Output surface mapping $(\alpha=1.0)$

\section{DISCUSSION AND CONCLUSION}

One underlying assumption of the proposed methodology is that the selection is made under certainty of the information data. In reality, the information available is highly uncertain and sometimes may be under risk also. The fuzzy $S$-curve MF helps in reducing the level of uncertainty as 
validated further by introducing the ANFIS model shown in Table 5. The root mean square errors as compared with the original values of level-ofsatisfaction $(\alpha)$ are very low, and the satisfaction level of the decision makers are, thus, appreciable as well as within the acceptable level.

\section{REFERENCES}

Abraham A., 2005, Adaptation of fuzzy inference system using neural learning, fuzzy system engineering: theory and practice. In: Nedjah, N. et al. (eds.), Studies in Fuzziness and Soft Computing, pp. 53-83, Springer Verlag, Germany.

Bhattacharya, A., Sarkar, B., and Mukherjee, S.K., 2005, Integrating AHP with QFD for robot selection under requirement perspective, International Journal of Production Research, 43(17): 3671-3685.

Chuang, P.T., 2001, Combining the analytic hierarchy process and quality function deployment for a location decision from a requirement perspective, International Journal of Advanced Manufacturing Technology, 18: 842-849.

Cohen, L., 1995, Quality Function Deployment - How to make QFD Work for You, Addison - Wesley, New York.

Franceśchini, F., and Rossetto, S., 1995, QFD: the problem of comparing technical/engineering design requirements, Research Engineering Design, 7: 270-278.

Govers, C.P.M., 2001, QFD not just a tool but a way of quality management, International Journal of Production Economics, 69(2): 151-159.

Hauser, J.R., and Clausing, D., 1988, The house of quality, Harvard Business Review, May - June: $63-73$.

Jang, J.S.R., 1991, ANFIS: adaptive network based fuzzy inference systems, IEEE Transactions Systems, Man \& Cybernetics, 23: 665-685.

Saaty, T.L., 1994, How to make a decision: the analytic hierarchy process, Interfaces, 24(6): 19-43.

Saaty, T.L., 1990, How to make a decision: the analytic hierarchy process, European Journal of Operational Research, 48(1): 9-26.

Saaty, T.L., 1988, The Analytic Hierarchy Process, Pergamon, New York.

Saaty, T.L., and Vargas, L.G., 1987, Uncertainty and rank order in the analytic hierarchy process, European Journal of Operational Research, 32: 107-117.

Saaty, T.L., 1980, The Analytical Hierarchy Process, McGraw-Hill, New Work.

Sugeno, M., 1985, Industrial Applications of Fuzzy Control, Elsevier Science Pub Co., New York.

Sullivan, L. P., 1986, Quality function deployment, Quality Progress, 19(6): 39-50.

Wasserman, G.S., 1993, On how to prioritize design requirements during the QFD planning process, IEEE Transactions, 25(3): 59-65. 